\title{
REVIEW
}

\section{CD154: the atherosclerotic risk factor in rheumatoid arthritis?}

\author{
Ghada S Hassann ${ }^{\dagger 1}$, Daniel Yacoub ${ }^{\dagger 1}$, Nada Alaaeddine², Amal Nadiri', Yahye Merhi ${ }^{3}$ and Walid Mourad ${ }^{* 1}$
}

\begin{abstract}
Atherosclerosis, now regarded as a chronic inflammatory disease of the arterial wall, and its clinical manifestations have increasingly been associated with rheumatoid arthritis (RA), supporting the notion that autoimmune diseases and vascular disorders share common etiological features. Indeed, evidence pertaining to this matter indicates that inflammation and its multiple components are the driving force behind the pathogenesis of these disorders. Interestingly, CD154 and its receptors have emerged as major players in the development of RA and atherosclerosis, which raises the possibility that this axis may represent an important biological link between both complications. Indeed, CD154 signaling elicits critical inflammatory responses that are common to the pathogenesis of both diseases. Here, we provide an overview of the traditional and disease-related interrelations between RA and vascular abnormalities, while focusing on CD154 as a potential mediator in the development of atherosclerotic events in RA patients.
\end{abstract}

\section{Introduction}

Although CD154 was initially recognized for its pivotal role in humoral responses, multiple lines of evidence now support its implication in various immune and inflammatory conditions such as rheumatoid arthritis (RA). CD154 activates numerous cells of critical importance in the pathogenesis of RA, inducing responses such as cytokine release, matrix degradation and autoantibody production, all of which promote disease development [1]. Furthermore, CD154 mediates inflammatory events

${ }^{+}$Contributed equally to this work

*Correspondence: mw.mourad @umontreal.ca

'Laboratoire d'Immunologie Cellulaire et Moléculaire, Centre Hospitalier de

I'Université de Montréal, Hôpital Saint-Luc, Pavillon Edward Asselin, Local: 415,

264 René Lévesque Est, Montréal, QC H2X 1P1, Canada

Full list of author information is available at the end of the article through its action on various vascular cells, leading to atherogenesis initiation and progression [2].

Interestingly, cardiovascular complications such as atherosclerosis and its clinical sequelae have increasingly been associated with autoimmune diseases. Indeed, RA patients exhibit increased morbidity and mortality rates, which are associated with cardiovascular events such as acute coronary syndromes originating from atherosclerotic complications [3]. Overwhelming evidence now highlights the importance of inflammatory pathways in the pathogenesis of atherosclerosis, thereby supporting that both these diseases share common etiological components [4]. Given its contribution to the pathophysiology of autoimmune diseases and atherosclerosis, CD154 may represent the biological link between both of these disorders as an important risk factor in the development of accelerated vascular complications described in RA patients [5].

In this review we illustrate the role of CD154 in RA and atherosclerosis, while highlighting its potential implication in the increased vascular events associated with autoimmune conditions. We also discuss other traditional or disease-related factors contributing to atherosclerotic events in RA patients.

\section{Structure and function of CD154 and its specific receptors \\ CD154}

CD154, also known as CD40 ligand, is a member of the TNF superfamily initially described on T cells [6] but also found on platelets, monocytes and dendritic cells, as well as nonhematopoietic cells including endothelial cells, smooth muscle cells, fibroblasts and others. CD154 was originally shown to play a significantly role in T-dependent B-lymphocyte responses [7]. In addition to its key role in humoral immunity, CD154 also mediates a vast array of inflammatory pathways, as evident by its involvement in cellular immunity. These include priming and expansion of $\mathrm{T}$ cells and the activation of antigen-presenting cells and other vascular cells, whereby CD154 was shown to upregulate costimulatory molecules and cytokine production [8]. These cellular events are also the main mechanisms by 
which CD154 regulates numerous inflammatory disorders, including RA and vascular diseases.

\section{CD154 receptors}

\section{CD40}

CD40, a glycoprotein from the TNF receptor family, is the classical high-affinity receptor for CD154. CD40 is constitutively or inducibly expressed by most cells of the vascular and immune system (hematopoietic cells and nonhematopoietic cells) and represents the main signaling molecule in the CD154/CD40 receptor-ligand pair [8]. This interaction is required for immunoglobulin isotype switching during the immune response. In fact, patients suffering from the $\mathrm{X}$-linked hyperimmunoglobulin-M syndrome, which results from a genetic mutation in the CD154 gene, fail to produce the immunoglobulins IgG, IgA and IgE as a consequence of deficient CD40 signaling in B cells [9]. Indeed, during humoral immunity, a tight interplay between dendritic cells, $\mathrm{T}$ lymphocytes and $\mathrm{B}$ lymphocytes occurs, throughout which the activation of CD40 provides a crucial signal for the activation, differentiation and secretion of immunoglobulins by $B$ cells [10].

In addition to its pivotal role in adaptive immunity, CD40 ligation generally leads to cell survival and inhibition of apoptosis, critical features of inflammatory cell resistance and exacerbation during CD154-mediated autoimmune and vascular diseases. These responses are mainly dependent upon the activation of the anti-apoptotic proteins $\mathrm{Bcl}-\mathrm{XL}, \mathrm{A} 20, \mathrm{Bfl}-1$ and $\mathrm{Mcl}-1$, which protect against Fas ligand and TNF-induced cell death [11]. CD40 signaling also plays an important role in cell-mediated immunity, through its involvement in the upregulation of a plethora of proinflammatory adhesion molecules, cytokines, chemokines, matrix metalloproteinases (MMPs) and procoagulants. For instance, $\mathrm{CD} 40$ ligation on synovial cells induces TNF $\alpha$ and IL-1 $\beta$ production, critical inflammatory mediators of RA pathogenesis [12].

The CD154/CD40 axis also regulates the expression and activation of MMP-1, MMP-9 and MMP-3 on monocytes, which contribute to a deleterious degradative cycle in RA $[13,14]$. Through these inflammatory pathways, and multiple others, CD40 signaling has been linked to RA development. Indeed, CD154/CD40 signaling plays a critical role in the initiation and progression of the mouse collagen-induced arthritis model, as demonstrated by both pharmacological and genetic approaches (this aspect is also discussed in further detail below) $[15,16]$. Moreover, CD40 activation on endothelial cells triggers the release of various inflammatory mediators of critical importance in the initiation and development of vascular disorders such as atherosclerosis [17].

Although most vascular and immune complications associated with CD154 have been largely attributed to its interaction with $\mathrm{CD} 40$, recently identified additional receptors merit attention. These include the integrins $\alpha \operatorname{IIb} \beta 3, \alpha 5 \beta 1$ and $\alpha M \beta 2$ (Figure 1).

\section{allb $\beta$}

The $\alpha$ IIb $\beta 3$ integrin is abundantly expressed on the surface of platelets and mediates platelet aggregation and adhesion. Binding to its natural ligands, such as fibrinogen, is dependent upon inside-out-mediated conformational activation of the molecule, a phenomenon shared by all members of the integrin family. Interestingly, a KGD sequence can be found within the extracellular domain of the CD154 molecule, thereby allowing binding to the KGD recognition motif of $\alpha \operatorname{IIb} \beta 3$.

Binding of CD154 to $\alpha \operatorname{IIb} \beta 3$ was shown to induce phosphorylation of tyrosine residues within the cytoplasmic domain of the $\beta 3$ subunit and appears essential for thrombus stabilization in vivo $[18,19]$. Indeed, CD154 ${ }^{-/-}$mice exhibit unstable thrombi, which can be overcome by infusion of wildtype recombinant human CD154 and not CD154 specifically mutated at the site of interaction with $\alpha \operatorname{IIb} \beta 3$ [18]. These results highlight the importance of the CD154/ $\alpha \operatorname{IIb} \beta 3$ interaction in platelet function and thrombus formation, although additional studies are needed to further consolidate the implication of this new dyad in thromboinflammatory reactions.

\section{$\alpha 5 \beta 1$}

The fibronectin $\alpha 5 \beta 1$ integrin receptor was also shown to bind CD154 [20]. Cells of the undifferentiated human monocytic U937 cell line can interact with soluble CD154 (sCD154) in a CD40-independent and $\alpha I I b \beta 3$-independent manner. Binding appears to be mediated by $\alpha 5 \beta 1$, since preincubation with anti- $\alpha 5 \beta 1$ antibodies or soluble $\alpha 5 \beta 1$ reverses the interaction of sCD154 to this cell line. Interestingly, CD154 can interact with both $\mathrm{CD} 40$ and $\alpha 5 \beta 1$ concomitantly, as co-incubation of sCD154 with soluble CD40 does not affect binding to $\alpha 5 \beta 1$, indicating that $\mathrm{CD} 40$ and $\alpha 5 \beta 1$ share distinct binding residues for CD154 [20,21].

Unlike $\alpha \operatorname{IIb} \beta 3, \mathrm{CD} 154$ interacts with constitutively inactive $\alpha 5 \beta 1$, which is uncommon to the classical scheme of integrin outside-in signaling and activation. This observation was demonstrated by experiments in which activation of $\alpha 5 \beta 1$ by chemical agents such as DTT hinders the binding to sCD154. Moreover, bronchial fibroblasts obtained from asthmatic subjects have been previously shown to interact with CD154 from $\mathrm{T}$ cells in a $\alpha 5 \beta 1$-dependent manner, suggesting the existence of CD154/ $\alpha 5 \beta 1$ cross-talk in inflammatory airway diseases such as asthma [22]. Nevertheless, the physiological relevance of this interaction remains unexplored and additional studies are needed to fully characterize the exact contribution of this novel CD154 binding partner in inflammatory disorders. 


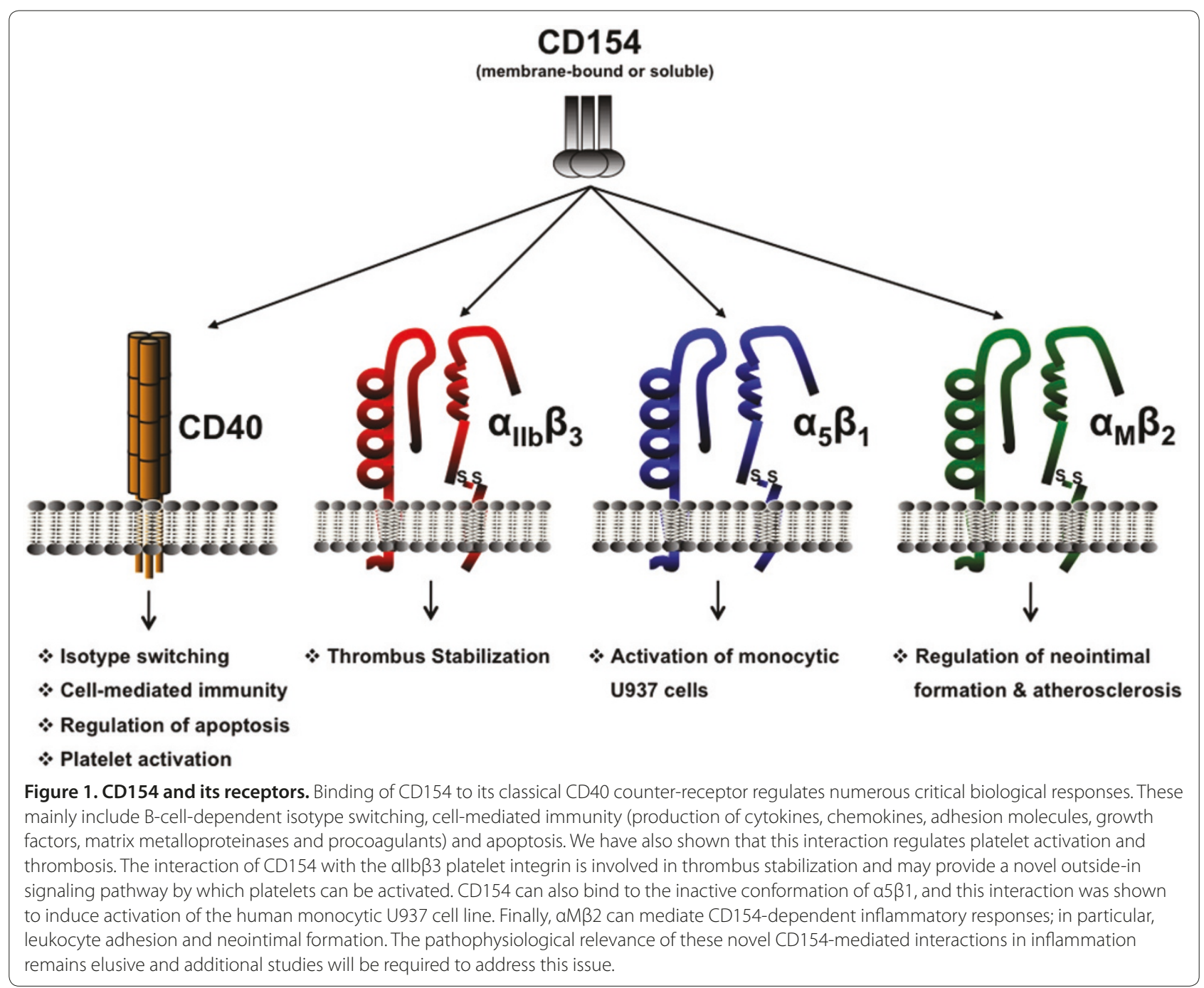

\section{$\alpha M \beta 2$}

The $\alpha \mathrm{M} \beta 2$ (Mac-1) integrin mediates firm adhesion of leukocytes to inflamed vessels by interacting with its endothelial cell counter-receptor intercellular adhesion molecule-1. CD154 is also able to interact with this integrin, and this interaction may represent an alternative pathway for CD154-mediated inflammation. Indeed, inhibition of this novel CD154 binding partner significantly attenuates leukocyte accumulation at sites of inflammation and reduces atherogenesis, indicating that CD154 may promote, at least in part, atherosclerotic lesions in a $\alpha \mathrm{M} \beta 2$-dependent manner. This hypothesis was recently demonstrated in an elegant study showing that specific targeting of this dyad with small inhibitory peptides significantly reduces atherogenesis and inflammatory cell recruitment, but does not affect thrombosis and immunity [23]. These data imply that CD154/ $\alpha M \beta 2$ interactions play a specific role in inflammatory-driven diseases in which leukocyte recruitment and infiltration at the sites of lesions represent important hallmarks of disease initiation. Specific targeting of this interaction has now emerged as a potential treatment strategy against inflammatory diseases, as compared with global CD154 inhibition where immunodeficiency and bleeding complications could be observed.

\section{Role of CD154 in rheumatoid arthritis}

$\mathrm{RA}$ is an autoimmune condition belonging to the rheumatic inflammatory diseases, and is characterized by chronic inflammation of the synovial lining of joints. RA implicates many immune and inflammatory cells including lymphocytes, neutrophils, mast cells, and synovial tissue cells themselves [24]. Figure 2 illustrates the biological significance of CD154 in RA and RA-related atherosclerosis. RA patients exhibit increased expression of CD154 on many vascular and synovial cell types. Indeed, $\mathrm{CD}^{+} \mathrm{T}$ cells, which are involved in cytokine and MMP production in the synovial fluid of RA patients, 


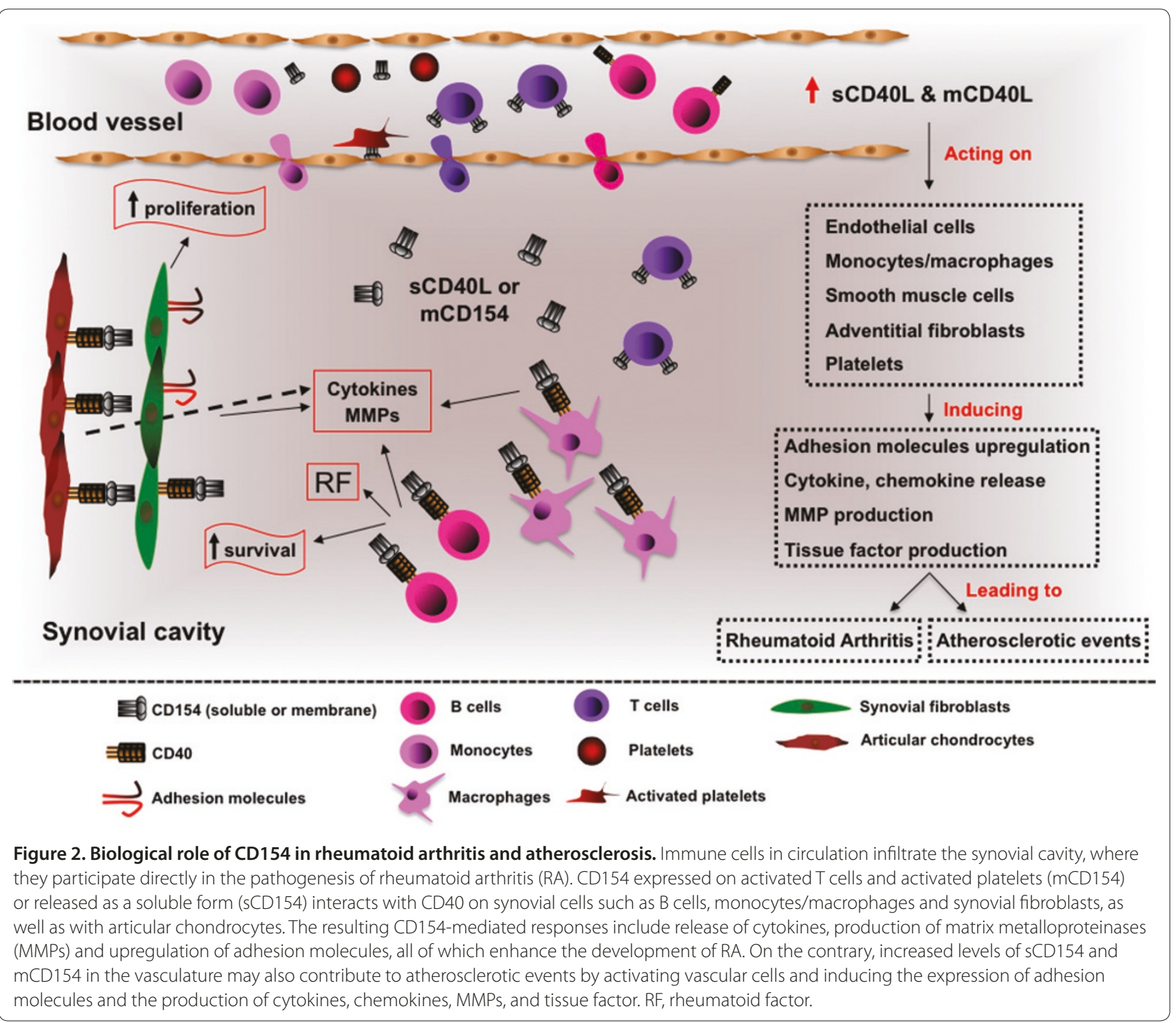

were shown to exhibit upregulation of cell surface CD154 [25]. In addition, by interacting with its CD40 receptor on B cells, CD154 was reported to mediate B-cell survival and production of rheumatoid factor (RF), an important mediator in RA [26]. Further immune-inflammatory functions of CD154 include the release of cytokines/ chemokines, the production of MMPs and the upregulation of adhesion molecules in other cell types known to play critical roles in the pathogenesis of RA - namely, synovial monocytes/macrophages, fibroblasts and articular chondrocytes [27].

Data from RA animal models convincingly support the role of CD154 in the pathogenesis of the disease, as antiCD154 treatment was shown to attenuate inflammatory events and disease severity [28]. Moreover, administration of agonistic anti-CD40 antibodies in mice exacerbates disease progression and IFN $\gamma$ production by $\mathrm{T}$ cells
[15]. Gene silencing of CD40 through siRNA targeting prevents the development of the disease in mice, further supporting the contribution of CD40 in the pathogenesis of RA [16]. The importance of the CD154 axis in RA is also highlighted by the levels of $\mathrm{SCD} 154$ found in patients, which correlate with disease severity and both IgM-RF and IgG-RF titers [29]. Interestingly, in a casecontrol cohort study in Spanish females, an association between RA and a specific allele variant within the CD154 gene was established. Indeed, authors found that patients with RA express lower frequencies of the 24CAs allele than control patients, thereby linking the CD154 system to RA risk [30].

\section{Role of CD154 in atherosclerosis}

Atherosclerosis is a chronic disease of the vessels involving many inflammatory and immune events. In the 
presence of proper risk factors and inflammatory stimuli, the initial atherosclerotic lesion can develop into a growing fibrous plaque prone to rupture. If left untreated, plaque rupture may ensue, leading to thromboinflammatory reactions and vascular complications such as acute coronary syndromes, cerebrovascular diseases and others [31]. Accumulating evidence indicates that CD154 is implicated in all stages of the pathogenesis of atherosclerosis since targeting of this molecule by both pharmacological and genetic approaches significantly reduces the size and lipid contents of atherosclerotic lesions [32,33].

In the initial steps, CD154 is involved in endothelial cell activation, a critical step of atherogenesis initiation. CD154-dependent activation of endothelial cells induces expression of adhesion molecules and production of cytokines, which result in the recruitment and infiltration of inflammatory cells into the subendothelial space. Thereafter, CD154 further amplifies the inflammatory response by inducing additional cytokine release, production of MMPs and expression of tissue factor in cells of the growing atherosclerotic lesion, mainly macrophages and smooth muscle cells. These CD154-mediated cellular responses contribute to plaque instability and vulnerability to rupture, thereby initiating thrombotic events and clinical manifestations [31].

CD154 has therefore emerged as an independent and strong risk factor for atherosclerosis. Indeed, enhanced levels of sCD154 have been linked to acute coronary syndromes and correlate with disease prognosis [34]. In addition, CD154 may be involved in the thrombotic events that follow atherosclerotic plaque rupture. In this regard, we have shown that $\mathrm{SCD} 154$ primes and enhances agonist-induced activation and aggregation of human platelets through a CD40-mediated TNF receptorassociated factor-2/Rac1/p38 mitogen-activated protein kinase-dependent pathway, which ultimately leads to platelet shape change and actin polymerization. Moreover, we have demonstrated that enhanced levels of sCD154 exacerbate thrombus formation and leukocyte infiltration in response to vascular injury, in a CD40dependent manner [35]. More recently, we demonstrated that the CD154/CD40 axis triggers NF- $\mathrm{KB}$ activation in platelets. This signaling pathway plays a critical role in platelet activation and aggregation upon sCD154 stimulation and may represent an important target against atherothrombosis [36].

\section{Rheumatoid arthritis and vascular risk}

RA patients were shown to exhibit increased mortality associated with atherosclerosis compared with the general population [3,37]. The cardiovascular risk even precedes the formal American College of Rheumatology criteria-based diagnosis of RA, indicating an early association between both complications [38]. Moreover, disease severity directly correlates with the risk of developing vascular complications, since more advanced disease states seem to predict greater cardiovascular morbidity in RA patients [3].

Given the immunoinflammatory nature of atherosclerosis, interest has been focused on the association between inflammatory autoimmune diseases and vascular events. Indeed, cardiovascular complications have been described in RA, systemic lupus erythematosus, ankylosing spondylitis, psoriasis, primary anti-phospholipid syndrome, systemic sclerosis or scleroderma and other disorders of inflammatory nature [39]. Various stages of atherosclerosis, ranging from preclinical events to disease manifestations and complications, have been described in patients with RA. Endothelial dysfunction, the initial step in the development of atherosclerotic lesions, is detected early in RA patients, as indicated by impaired flow-mediated dilation. In longer disease durations, more structural damage is observed in the arteries, as measured by increased common carotid intima/media thickness [40]. RA severity has been associated with prevalence and extent of calcified lesions in coronary arteries [41]. Interestingly, a significant interaction was found between many atherosclerotic risk factors and RA parameters, suggesting a synergy between RA modulators and these traditional risk factors in the development and/or acceleration of atherosclerosis [42].

\section{Common risk factors of rheumatoid arthritis and atherosclerosis}

RA and atherosclerosis share a number of risk factors (Table 1). Smoking, which represents a major atherogenic risk factor, was also found to be associated with RA severity and prognosis in patients harboring the HLA-DR shared epitope or in patients positive for anti-citrullinated protein antibodies (ACPA), two critical biomarkers of RA [43,44]. Interestingly, the RA susceptibility HLADR gene was shown to correlate with cardiovascular events in RA patients, especially if combined with smoking and the presence of high autoantibody levels [45]. Other proatherogenic factors - including diabetes mellitus, upregulated levels of lipokines such as resistin and leptin, and decreased production of the antiinflammatory factor adiponectin - are also exhibited in RA patients [46,47]. In addition to these common risk factors, RA and atherosclerosis share a number of underlying mechanisms of autoimmune and inflammatory nature.

\section{Autoantibodies in rheumatoid arthritis and atherosclerosis}

Autoimmune manifestations are the hallmark features of RA and are now increasingly reported in patients with atherosclerotic events. RF and ACPA are the main 
Table 1. Common risk factors of rheumatoid arthritis and atherosclerosis

\begin{tabular}{lcc}
\hline & $\begin{array}{c}\text { Rheumatoid } \\
\text { arthritis }\end{array}$ & Atherosclerosis \\
\hline Smoking & $\checkmark$ & $\checkmark$ \\
Diabetes mellitus & $\checkmark$ & $\checkmark$ \\
Lipokine levels & $\checkmark$ & $\checkmark$ \\
Rheumatoid factor & $\checkmark$ & \\
Anti-citrullinated protein antibodies & $\checkmark$ & \\
Anti-cyclic citrullinated peptides & $\checkmark$ & \\
Anti-RA33 & $\checkmark$ & \\
Anti-collagen II & $\checkmark$ & $\checkmark$ \\
Anti-heat shock protein 65 & $\checkmark$ & $\checkmark$ \\
Anti-oxidized low-density lipoprotein & & $\checkmark$ \\
Anti- $\beta_{2}$-glycoprotein I & & $\checkmark$ \\
C-reactive protein & $\checkmark$ & $\checkmark$ \\
TNFa & $\checkmark$ & $\checkmark$ \\
IL-1, IL-6 & $\checkmark$ & $\checkmark$ \\
IFNy & $\checkmark$ & $\checkmark$ \\
Monocyte chemoattractant protein-1 & $\checkmark$ & $\checkmark$ \\
\hline
\end{tabular}

autoimmune antibodies present in RA. RF is directed against the Fc portion of IgGs, while ACPA are directed against fibrin, fibrinogen and vimentin post-translationally modified to contain the amino acid citrulline [48].

Even though RF can be detected in other diseases or in healthy individuals, it remains an important marker of RA in terms of diagnostic support and evaluation of disease progression risk $[49,50]$. Moreover, anti-cyclic citrullinated peptide antibodies have also emerged as reliable diagnostic markers of early RA-associated events and can be used as sensitive test substrates for detecting ACPA in patients [51]. Notably, anti-cyclic citrullinated peptide antibodies have been previously associated with subclinical atherosclerosis in patients with RA, indicating that they may represent important risk factors in the development of accelerated cardiovascular events in these patients [52].

Other autoimmune antibodies present at high levels in RA include anti-RA33 directed against heterogeneous nuclear ribonucleoprotein $\mathrm{A}_{2}$, anti-collagen directed against collagen II and antibodies directed against heat shock proteins (HSPs) [48]. On the contrary, atherosclerosis was also shown to be associated with a number of self-antigens, including oxidized low-density lipoprotein, $\beta_{2}$-glycoprotein I, as discussed below, and HSP60/65 [53,54]. Interestingly, immunizing atherosclerosis-prone animals with the HSP60 autoantigen or infusion of lymphocytes directed against this particular antigen was shown to enhance disease progression.
Auto-HSP60 antibodies are also detected in sera of patients with RA [55]. Generation of autoantibodies in RA could therefore be implicated in enhancing atherosclerotic events in patients suffering with this disease.

\section{Inflammation in rheumatoid arthritis and atherosclerosis}

In addition to their shared autoimmune manifestations, RA and atherosclerosis are also interrelated through their tight inflammatory nature. Indeed, both disease conditions are characterized by $\mathrm{T}$-cell and macrophage activation. In addition, patients with RA exhibit an upregulation of the inflammatory marker C-reactive protein, a strong biomarker of cardiovascular risk. Proinflammatory cytokines, including TNF $\alpha$, IL-1, IL-6 and IFN $\gamma$, and chemokines such as monocyte chemoattractant protein-1 were also shown to be involved in the pathophysiology of RA and atherosclerosis [31,56]. Moreover, both diseases show an upregulation of endothelial and immune cell adhesion molecules, as well as an increased production and activity of MMPs $[31,56]$.

\section{CD154 as an atherosclerotic risk factor in rheumatoid arthritis}

Because of its significant role in the pathology of atherosclerosis and autoimmune conditions such as RA, CD154 could represent an important link between both conditions by contributing to the increased prevalence of vascular diseases seen in RA patients. CD154, both soluble and membrane bound, is upregulated in the synovial cavity of RA patients and could therefore initiate vascular inflammatory events or, at the least, enhance an already established vascular abnormality (Figure 2). Evidence that CD154 may be linked to vascular complications in RA patients was initially provided by a study assessing levels of sCD154 in RA and rheumatoid vasculitis, which is characterized by extra-articular inflammation of small and medium-sized blood vessels. Authors found that levels of sCD154 were significantly higher in RA patients who had vasculitis than those without, indicating that CD154 may represent an important etiological factor of vascular inflammatory development in these patients [29]. Moreover, in a study aiming at investigating the association between RA and atherosclerotic events by assessing platelet, endothelial and coagulation activation markers, serum levels of sCD154 were significantly increased in RA patients as compared with controls [57].

Because sCD154 in circulation is mainly released from activated platelets, it is regarded as an important marker of platelet activation. The above findings may explain, at least in part, the mechanisms by which platelets contribute to both atherosclerosis and RA (Figure 3). Indeed, platelets have been shown to play an important 
role in the pathophysiology of RA, although the precise underlying mechanisms remain unknown. Patients with RA were shown to present with increased levels of circulating platelet microparticles, which originate from the shedding of platelet plasma membranes. These patients also exhibit an upregulation of platelet activation markers, including sCD154 [58]. Moreover, Boilard and colleagues observed the presence of platelet microparticles in joint fluids of patients with RA [59]. The formation of these platelet microparticles was dependent upon the recruitment of platelets within the lining of the synovial cavity via the collagen-specific GPVI receptor and their interaction with fibroblast-like cells. Reciprocally, platelet microparticles can stimulate fibroblast-like cells to induce the release of cytokines (IL-6) and chemokines (IL-8) of crucial importance in RA pathology [59]. More recently, the same authors also outlined a role for platelets themselves rather than their microparticles in the pathology of inflammatory arthritis via a fibroblastinduced production of prostacyclin [60]. However, these studies did not investigate the possible contribution of platelet CD154 in the pathology of RA, as synovial fibroblasts express the CD154 receptor, CD40 [8]. Nevertheless, these findings provide important evidence for the existing link between inflammatory vascular effectors such as platelets and their mediators (CD154 perhaps) and autoimmune pathophysiology.

Recently, a polymorphism in the CD40 gene was found to be associated with atherothrombotic manifestations in RA patients, thereby supporting the implication of this axis in the development of accelerated vascular complications in RA [61]. Additional evidence for the contribution of the CD154 axis in the association between RA and atherosclerosis was also described in a study showing that abrogating vasoactive factors such as angiotensin II can affect vascular function and inflammatory markers in RA patients. The authors demonstrate that inhibiting the angiotensin-converting enzyme in RA patients ameliorates arterial endothelial function and downregulates plasmatic levels of soluble CD40 and TNF $\alpha$ [62]. Downregulation of these critical inflammatory molecules may represent the underlying mechanism by which vascular functions are significantly improved in RA patients treated with angiotensin-converting enzyme inhibitors.

\section{Conclusion}

Growing evidence favors the implication of CD154 in the cross-talk between autoimmune diseases and atherosclerosis, contributing as such to the enhancement of vascular abnormalities in these conditions. CD154 could therefore represent an interesting target for preventive or therapeutic strategies aiming at decreasing atherosclerotic load in autoimmune diseases. Many traditional, autoimmune and inflammatory mechanisms have been

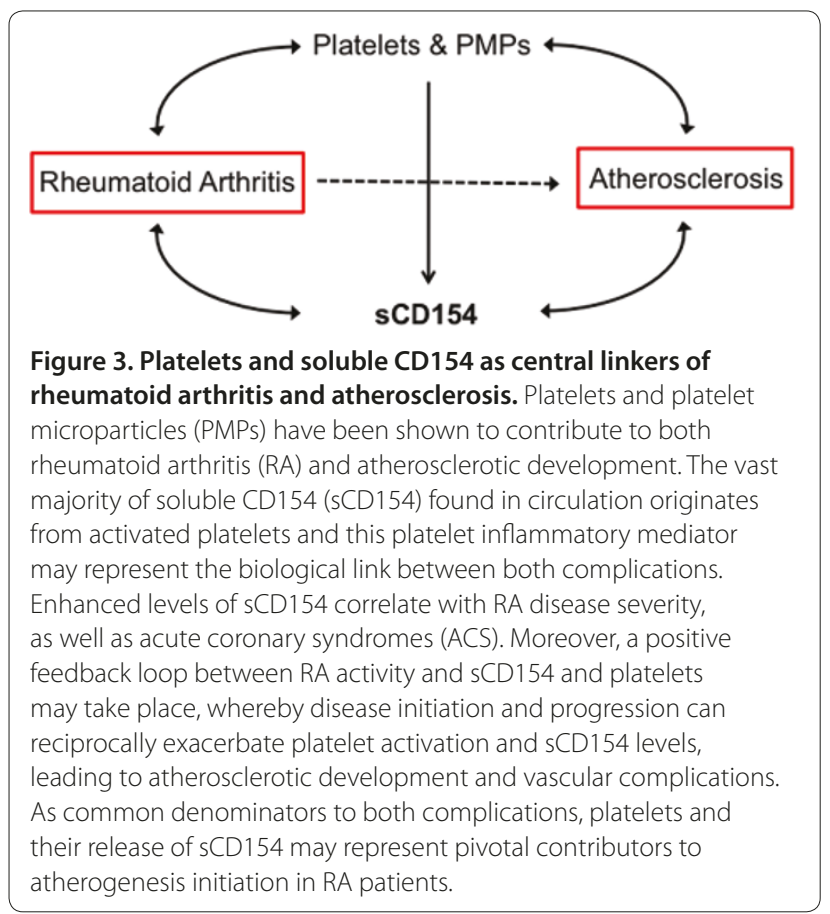

targeted in the goal of improving vascular functions in patients with autoimmune disorders. Cholesterol-lowering drugs such as statins, also known for their antiinflammatory actions, have shown beneficial anti-inflammatory effects with modification of vascular risk factors in RA patients [63]. Statins also have beneficial effects in reducing $\mathrm{RA}$ disease activity itself, consolidating again the notion that both diseases are intimately linked [64]. Inhibition of inflammatory pathways induced by the vasoactive factor angiotensin II also improves vascular functions in RA patients.

Interestingly, current RA therapies such as TNF $\alpha$ inhibitors (infliximab, adalimumab and etanercept) have been shown to be effective in controlling disease activity, while providing significant benefits in the management of vascular complications observed in these patients. For instance, positive effects on carotid intima-media thickness, arterial stiffness and endothelial dysfunction have been reported in RA patients treated with TNF antagonists [65]. However, multiple studies have determined that TNF blockage increases total cholesterol levels (triglycerides, low-density lipoproteins and high-density lipoproteins) in RA patients, putting in doubt the level of efficacy of these treatments in reducing cardiovascular events in patients with autoimmune diseases such as RA [65]. Moreover, nonsteroidal anti-inflammatory drugs such as cyclooxygenase- 2 inhibitors for the treatment of RA have been associated with an increased risk of developing cardiovascular events, indicating that these agents may not represent a suitable therapeutic option for decreasing atherosclerotic load in these patients [66]. 
Because of its critical role as a common factor in the pathogenesis of atherosclerosis and autoimmune diseases, blocking CD154 interactions may show beneficial results in the treatment of vascular complications associated with autoimmune diseases or in the treatment of autoimmune diseases themselves. Unfortunately, direct clinical evidence for the role of CD154 as a contributor to accelerated vascular complications in RA patients has been hindered by the fact that pre-existing trials using anti-CD154 antibodies induce thromboembolic complications in treated patients, perhaps through unwanted Fc activation at the surface of platelets [67]. These side effects have impeded the continuation of ongoing trials, and no clinical data on the effect of anti-CD154 therapy on the occurrence of vascular complications in autoimmune patients have been provided. Further studies will be necessary to fully establish the role of CD154 in the development of accelerated cardiovascular events in RA patients. The development of novel anti-CD154 agents may render better clinical outcomes, while providing affirmation of this axis as a linker of autoimmune diseases and cardiovascular complications.

\section{Abbreviations}

ACPA, anti-citrullinated protein antibodies; HSP, heat shock protein; IFN, interferon; IL, interleukin; MMP, matrix metalloproteinase; NF, nuclear factor; $R A$, rheumatoid arthritis; RF, rheumatoid factor; SCD154, soluble CD154; siRNA, small interfering RNA; TNF, tumor necrosis factor.

\section{Competing interests}

The authors declare that they have no competing interests.

\section{Acknowledgments}

Work in our laboratories is supported by the Canadian Institutes of Health Research and the Canadian Arthritis Network.

\section{Author details}

'Laboratoire d'Immunologie Cellulaire et Moléculaire, Centre Hospitalier de I'Université de Montréal, Hôpital Saint-Luc, Pavillon Edward Asselin, Local: 415, 264 René Lévesque Est, Montréal, QC H2X 1P1, Canada. 2Department of Pathology, Faculty of Medicine, PO Box 11-5076, St Joseph University, Beirut, Lebanon. ${ }^{3}$ Institut de Cardiologie de Montréal, Université de Montréal, Montréal, QC H1T 1C8, Canada.

Published: 22 February 2013

\section{References}

1. Peters AL, Stunz LL, Bishop GA: CD40 and autoimmunity: the dark side of a great activator. Semin Immunol 2009, 21:293-300.

2. Schonbeck U, Libby P: CD40 signaling and plaque instability. Circ Res 2001, 89:1092-1103

3. Van Doornum S, McColl G, Wicks IP: Accelerated atherosclerosis: an extraarticular feature of rheumatoid arthritis? Arthritis Rheum 2002, 46:862-873

4. Montecucco F, Mach F: Atherosclerosis is an inflammatory disease. Semin Immunopathol 2009, 31:1-3.

5. Cavagna L, Boffini N, Cagnotto G, Inverardi F, Grosso V, Caporali R: Atherosclerosis and rheumatoid arthritis: more than a simple association. Mediators Inflamm 2012, 2012:147354

6. van Kooten C, Banchereau J: CD40-CD40 ligand. J Leukoc Bio/ 2000, 67:2-17.

7. Foy T, Aruffo A, Bajorath J, Buhlmann J, Noelle R: Immune regulation by CD40 and its ligand GP39. Annu Rev Immunol 1996, 14:591-617.

8. Schonbeck U, Libby P: The CD40/CD154 receptor/ligand dyad. Cell Mol Life Sci2001, 58:4-43.
9. Hill A, Chapel H: X-linked immunodeficiency. The fruits of cooperation Nature 1993, 361:494

10. Ma DY, Clark EA: The role of CD40 and CD154/CD40L in dendritic cells. Semin Immunol 2009, 21:265-272.

11. Dallman C, Johnson PW, Packham G: Differential regulation of cell survival by CD40. Apoptosis 2003, 8:45-53.

12. Harigai M, Hara M, Nakazawa S, Fukasawa C, Ohta S, Sugiura T, Inoue K, Kashiwazaki S: Ligation of CD40 induced tumor necrosis factor-alpha in rheumatoid arthritis: a novel mechanism of activation of synoviocytes. J Rheumatol 1999, 26:1035-1043.

13. Malik N, Greenfield BW, Wahl AF, Kiener PA: Activation of human monocytes through CD40 induces matrix metalloproteinases. J Immunol 1996, 156:3952-3960.

14. Mach F, Schonbeck U, Bonnefoy JY, Pober JS, Libby P: Activation of monocyte/macrophage functions related to acute atheroma complication by ligation of CD40: induction of collagenase, stromelysin, and tissue factor. Circulation 1997, 96:396-399.

15. Tellander AC, Michaelsson E, Brunmark C, Andersson M: Potent adjuvant effect by anti-CD40 in collagen-induced arthritis. Enhanced disease is accompanied by increased production of collagen type-II reactive lgG2a and IFN-gamma. J Autoimmun 2000, 14:295-302.

16. Zheng X, Suzuki M, Zhang X, Ichim TE, Zhu F, Ling H, Shunnar A, Wang MH, Garcia B, Inman RD, Min WP: RNAi-mediated CD40-CD154 interruption promotes tolerance in autoimmune arthritis. Arthritis Res Ther 2010, 12:R13.

17. Henn V, Slupsky JR, Grafe M, Anagnostopoulos I, Forster R, Muller-Berghaus G, Kroczek RA: CD40 ligand on activated platelets triggers an inflammatory reaction of endothelial cells. Nature 1998, 391:591-594.

18. Andre P, Prasad KS, Denis CV, He M, Papalia JM, Hynes RO, Phillips DR, Wagner DD: CD40L stabilizes arterial thrombi by a beta3 integrin-dependent mechanism. Nat Med 2002, 8:247-252.

19. Prasad KS, Andre P, He M, Bao M, Manganello J, Phillips DR: Soluble CD40 ligand induces beta3 integrin tyrosine phosphorylation and triggers platelet activation by outside-in signaling. Proc Natl Acad Sci U S A 2003, 100:12367-12371.

20. Leveille C, Bouillon M, Guo W, Bolduc J, Sharif-Askari E, El-Fakhry Y, ReyesMoreno C, Lapointe R, Merhi Y, Wilkins JA, Mourad W: CD40 ligand binds to alpha5beta1 integrin and triggers cell signaling. J Biol Chem 2007, 282:5143-5151.

21. El Fakhry YE, Alturaihi H, Yacoub D, Liu L, Guo W, Leveille C, Jung D, Khzam LB, Merhi Y, Wilkins JA, Li H, Mourad W: Functional interaction of CD154 with a $\beta 1$ is totally independent from its binding to allb $\beta 3$ and CD40 molecules. J Biol Chem 2012, 287:18055-18066.

22. Loubaki L, Semlali A, Boisvert M, Jacques E, Plante S, Aoudjit F, Mourad W, Chakir J: Crosstalk between T cells and bronchial fibroblasts obtained from asthmatic subjects involves CD40L/a5 $\beta 1$ interaction. Mol Immunol 2010, 4:2112-2118.

23. Wolf D, Hohmann JD, Wiedemann A, Bledzka K, Blankenbach H, Marchini T, Gutte K, Zeschky K, Bassler N, Hoppe N, Rodriguez AO, Herr N, Hilgendorf I, Stachon P, Willecke F, Duerschmied D, von zur Muhlen C, Soloviev DA, Zhang L, Bode C, Plow EF, Libby P, Peter K, Zirlik A: Binding of CD40L to Mac-1's I-domain involves the EQLKKSKTL motif and mediates leukocyte recruitment and atherosclerosis - but does not affect immunity and thrombosis in mice. Circ Res 2011, 109:1269-1279.

24. Lee DM, Weinblatt ME: Rheumatoid arthritis. Lancet 2001, 358:903-911.

25. MacDonald KPA, Nishioka Y, Lipsky PE, Thomas R: Functional CD40 ligand is expressed by T cells in rheumatoid arthritis. J Clin Invest 1997, 100:2404-2414.

26. Kyburz D, Corr M, Brinson DC, Von Damm A, Tighe H, Carson DA: Human rheumatoid factor production is dependent on CD40 signaling and autoantigen. J Immunol 1999, 163:3116-3122

27. Hassan GS, Rana M, Léveillé C, Nadiri A, Jundi M, Polyak M, El-Fakhry Y, Mourad WM: Implication of CD154/CD40 interaction in healthy and autoimmune responses. Curr Immunol Rev 2009, 5:285-299.

28. Kyburz D, Carson DA, Corr M: The role of CD40 ligand and tumor necrosis factor alpha signaling in the transgenic $\mathrm{K} / \mathrm{BxN}$ mouse model of rheumatoid arthritis. Arthritis Rheum 2000, 43:2571-2577.

29. Tamura N, Kobayashi S, Kato K, Bando H, Haruta K, Oyanagi M, Kuriyama M, Kipps TJ, Hashimoto H: Soluble CD154 in rheumatoid arthritis: elevated plasma levels in cases with vasculitis. J Rheumatol 2001, 28:2583-2590.

30. Martin-Donaire T, Losada-Fernandez I, Perez-Chacon G, Rua-Figueroa I, Erausquin C, Naranjo-Hernandez A, Rosado S, Sanchez F, Garcia-Saavedra A, 
Citores MJ, Vargas JA, Perez-Aciego P: Association of the microsatellite in the $3^{\prime}$ untranslated region of the CD154 gene with rheumatoid arthritis in females from a Spanish cohort: a case-control study. Arthritis Res Ther 2007, 9:R89.

31. Hassan GS, Merhi Y, Mourad WM: CD154 and its receptors in inflammatory vascular pathologies. Trends Immunol 2009, 30:165-172.

32. Lutgens E, Gorelik L, Daemen MJ, de Muinck ED, Grewal IS, Koteliansky VE, Flavell RA: Requirement for CD154 in the progression of atherosclerosis. Nat Med 1999, 5:1313-1316.

33. Lutgens E, Cleutjens KB, Heeneman S, Koteliansky VE, Burkly LC, Daemen MJ Both early and delayed anti-CD40L antibody treatment induces a stable plaque phenotype. Proc Natl Acad Sci U S A 2000, 97:7464-7469.

34. Heeschen C, Dimmeler S, Hamm CW, van den Brand MJ, Boersma E, Zeiher AM, Simoons ML: Soluble CD40 ligand in acute coronary syndromes. N Engl J Med 2003, 348:1104-1111.

35. Yacoub D, Hachem A, Theoret JF, Gillis MA, Mourad W, Merhi Y: Enhanced levels of soluble CD40 ligand exacerbate platelet aggregation and thrombus formation through a CD40-dependent tumor necrosis factor receptor-associated factor-2/Rac1/p38 mitogen-activated protein kinase signaling pathway. Arterioscler Thromb Vasc Biol 2010, 30:2424-2433.

36. Hachem A, Yacoub D, Zaid Y, Mourad W, Merhi Y: Involvement of nuclear factor kappaB in platelet CD40 signaling. Biochem Biophys Res Commun 2012, 425:58-63

37. Abou-Raya A, Abou-Raya S: Inflammation: a pivotal link between autoimmune diseases and atherosclerosis. Autoimmun Rev 2006, 5:331-337.

38. Maradit-Kremers H, Crowson CS, Nicola PJ, Ballman KV, Roger VL, Jacobsen SJ, Gabriel SE: Increased unrecognized coronary heart disease and sudden deaths in rheumatoid arthritis: a population-based cohort study. Arthritis Rheum 2005, 52:402-411.

39. Alexandroff AB, Pauriah M, Camp RD, Lang CC, Struthers AD, Armstrong DJ: More than skin deep: atherosclerosis as a systemic manifestation of psoriasis. Br J Dermatol 2009, 161:1-7.

40. Kerekes G, Szekanecz Z, Der H, Sandor Z, Lakos G, Muszbek L, Csipo I, Sipka S, Seres I, Paragh G, Kappelmayer J, Szomják E, Veres K, Szegedi G, Shoenfeld Y, Soltész P: Endothelial dysfunction and atherosclerosis in rheumatoid arthritis: a multiparametric analysis using imaging techniques and laboratory markers of inflammation and autoimmunity. J Rheumatol 2008 , 35:398-406.

41. Salmon JE, Roman MJ: Subclinical atherosclerosis in rheumatoid arthritis and systemic lupus erythematosus. Am J Med 2008, 121(10 Suppl 1):S3-S8

42. del Rincon I, Freeman GL, Haas RW, O'Leary DH, Escalante A: Relative contribution of cardiovascular risk factors and rheumatoid arthritis clinical manifestations to atherosclerosis. Arthritis Rheum 2005, 52:3413-3423.

43. Padyukov L, Silva C, Stolt P, Alfredsson L, Klareskog L: A gene-environment interaction between smoking and shared epitope genes in HLA-DR provides a high risk of seropositive rheumatoid arthritis. Arthritis Rheum 2004, 50:3085-3092.

44. Szodoray P, Szabo Z, Kapitany A, Gyetvai A, Lakos G, Szanto S, Szucs G, Szekanecz Z: Anti-citrullinated protein/peptide autoantibodies in association with genetic and environmental factors as indicators of disease outcome in rheumatoid arthritis. Autoimmun Rev 2010, 9:140-143.

45. Farragher TM, Goodson NJ, Naseem H, Silman AJ, Thomson W, Symmons D, Barton A: Association of the HLA-DRB1 gene with premature death, particularly from cardiovascular disease, in patients with rheumatoid arthritis and inflammatory polyarthritis. Arthritis Rheum 2008, 58:359-369.

46. Dessein PH, Joffe BI, Stanwix AE: Inflammation, insulin resistance, and aberrant lipid metabolism as cardiovascular risk factors in rheumatoid arthritis. J Rheumatol 2003, 30:1403-1405.

47. Gonzalez-Gay MA, Llorca J, Garcia-Unzueta MT, Gonzalez-Juanatey C, De Matias JM, Martin J, Redelinghuys M, Woodiwiss AJ, Norton GR, Dessein PH: High-grade inflammation, circulating adiponectin concentrations and cardiovascular risk factors in severe rheumatoid arthritis. Clin Exp Rheumatol 2008, 26:596-603.

48. Mewar D, Wilson AG: Autoantibodies in rheumatoid arthritis: a review. Biomed Pharmacother 2006, 60:648-655.

49. Aletaha D, Neogi T, Silman AJ, Funovits J, Felson DT, Bingham CO, 3rd, Birnbaum NS, Burmester GR, Bykerk VP, Cohen MD, Combe B, Costenbade KH, Dougados M, Emery P, Ferraccioli G, Hazes JM,Hobbs K, Huizinga TW, Kavanaugh A, Kay J, Kvien TK, Laing T, Mease P, Ménard HA, Moreland LW,Naden RL, Pincus T, Smolen JS, Stanislawska-Biernat E, Symmons D, Tak PP, Upchurch KS, Vencovsky J, Wolfe F, Hawker G: 2010 rheumatoid arthritis classification criteria: an American College of Rheumatology/European League Against Rheumatism collaborative initiative. Ann Rheum Dis 2010, 69:1580-1588

50. Aletaha D, Alasti F, Smolen JS: Rheumatoid factor determines structural progression of rheumatoid arthritis dependent and independent of disease activity. Ann Rheum Dis 2012. [Epub ahead of print]

51. van Venrooij WJ, van Beers JJ, Pruijn GJ: Anti-CCP antibodies: the past, the present and the future. Nat Rev Rheumatol 2011, 7:391-398.

52. Gerli R, Bartoloni Bocci E, Sherer Y, Vaudo G, Moscatelli S, Shoenfeld Y: Association of anti-cyclic citrullinated peptide antibodies with subclinical atherosclerosis in patients with rheumatoid arthritis. Ann Rheum Dis 2008, 67:724-725.

53. Foteinos G, Afzal AR, Mandal K, Jahangiri M, Xu Q: Anti-heat shock protein 60 autoantibodies induce atherosclerosis in apolipoprotein E-deficient mice via endothelial damage. Circulation 2005, 112:1206-1213.

54. Sherer $Y$, Zinger $H$, Shoenfeld $Y$ : Atherosclerosis in systemic lupus erythematosus. Autoimmunity 2010, 43:98-102.

55. Yokota SI, Hirata D, Minota S, Higashiyama T, Kurimoto M, Yanagi H, Yura T, Kubota $\mathrm{H}$ : Autoantibodies against chaperonin CCT in human sera with rheumatic autoimmune diseases: comparison with antibodies against other Hsp60 family proteins. Cell Stress Chaperones 2000, 5:337-346.

56. Montecucco F, Mach F: Common inflammatory mediators orchestrate pathophysiological processes in rheumatoid arthritis and atherosclerosis. Rheumatology (Oxford) 2009, 48(1):11-22.

57. Pamuk GE, Vural O, Turgut B, Demir M, Pamuk ON, Cakir N: Increased platelet activation markers in rheumatoid arthritis: are they related with subclinical atherosclerosis? Platelets 2008, 19:146-154

58. Sellam J, Proulle V, Jungel A, Ittah M, Miceli Richard C, Gottenberg JE, Toti F, Benessiano J, Gay S, Freyssinet JM, Mariette X: Increased levels of circulating microparticles in primary Sjogren's syndrome, systemic lupus erythematosus and rheumatoid arthritis and relation with disease activity. Arthritis Res Ther 2009, 11:R156.

59. Boilard E, Nigrovic PA, Larabee K, Watts GF, Coblyn JS, Weinblatt ME, Massarotti EM, Remold-O'Donnell E, Farndale RW, Ware J, Lee DM: Platelets amplify inflammation in arthritis via collagen-dependent microparticle production. Science 2010, 327:580-583

60. Boilard E, Larabee K, Shnayder R, Jacobs K, Farndale RW, Ware J, Lee DM: Platelets participate in synovitis via Cox-1-dependent synthesis of prostacyclin independently of microparticle generation. J Immuno/ 2011, 186:4361-4366.

61. Arlestig L, Rantapaa-Dahlqvist S: Polymorphisms of the genes encoding CD40 and growth differentiation factor 15 and in the 9p21.3 region in patients with rheumatoid arthritis and cardiovascular disease. J Rheumatol 2012, 39:939-945

62. Flammer AJ, Sudano I, Hermann F, Gay S, Forster A, Neidhart M, Kunzler P, Enseleit F, Periat D, Hermann M, Nussberger J, Luscher TF, Corti R, Noll G, Ruschitzka F: Angiotensin-converting enzyme inhibition improves vascular function in rheumatoid arthritis. Circulation 2008, 117:2262-2269.

63. McCarey DW, McInnes IB, Madhok R, Hampson R, Scherbakov O, Ford I, Capell HA, Sattar N: Trial of Atorvastatin in Rheumatoid Arthritis (TARA): doubleblind, randomised placebo-controlled trial. Lancet 2004, 363:2015-2021.

64. Okamoto H, Koizumi K, Kamitsuji S, Inoue E, Hara M, Tomatsu T, Kamatani N, Yamanaka H: Beneficial action of statins in patients with rheumatoid arthritis in a large observational cohort. J Rheumatol 2007, 34:964-968.

65. McKellar GE, McCarey DW, Sattar N, McInnes IB: Role for TNF in atherosclerosis? Lessons from autoimmune disease. Nat Rev Cardiol 2009, 6:410-417.

66. Bresalier RS, Sandler RS, Quan H, Bolognese JA, Oxenius B, Horgan K, Lines C, Riddell R, Morton D, Lanas A, Konstam MA, Baron JA; Adenomatous Polyp Prevention on Vioxx (APPROVe) Trial Investigators: Cardiovascular events associated with rofecoxib in a colorectal adenoma chemoprevention trial. N Engl J Med 2005, 352:1092-1102.

67. Langer F, Ingersoll SB, Amirkhosravi A, Meyer T, Siddiqui FA, Ahmad S, Walker $J \mathrm{M}$, Amaya M, Desai H, Francis JL: The role of CD40 in CD40L- and antibodymediated platelet activation. Thromb Haemost 2005, 93:1137-1146.

doi:10.1186/ar4153

Cite this article as: Hassan GS, et al: CD154: the atherosclerotic risk factor in rheumatoid arthritis? Arthritis Research \& Therapy 2013, 15:206 